\title{
EL BARROCO Y LAS OFRENDAS HUMANAS EN NUEVA ESPAÑA
}

\author{
POR \\ ELSA MALVIDO \\ Instituto Nacional de Antropología e Historia. México
}

La muerte ciriquisiaca

jalando su carretón

parece una sombra flaca

bailando en el malecón (1).

\section{INTRODUCCIÓN}

Después de treinta años de bordar alrededor de la muerte, hacer un trabajo sobre ofrendas humanas durante el barroco mexicano, me pareció algo simple y que podría realizarse en poco tiempo. Y claro la tarea no fue fácil, ya que tenemos algunos estudios sobre el tema para la época prehispánica o para el siglo XX, pero del barroco y del siglo XIX, sólo contamos con trabajos sobre historia del arte, en los que se incluyen menciones de la iconografía de la muerte.

La enorme tradición más bien mitológica, que se ha hecho del amor, burla, desprecio, etc. del mexicano por la muerte y de su origen prehispánico, han sido planteamientos que chocan conmigo, sobre todo después de entender que la base de la religión católica es la exaltación de la pasión y muerte de Jesucristo, con todo lo que ello implica el que Dios ofrendara su cuerpo por nosotros y que en particular, durante el barroco europeo y americano, fueron retomadas e inventadas con manifestaciones que,

(1) M. Diaz RoIG, Naranja dulce, limón partido. México, El Colegio de México, 1982 pág. 40. 
claramente, los separan de otros momentos históricos de la cristiandad (2).

En este trabajo, pues, intentaré plantear algunos modos y elementos de las ofrendas impuestas por la cultura occidental y recreadas en la Nueva España, usando como contrapunto algunas ofrendas, que distintos grupos nativos continuaron haciendo a sus dioses, a pesar de la represión de que fueron víctimas. Aunque, insisto en aclarar, que sólo daré algunas pautas, ya que el tema requiere de una investigación más profunda.

Ahora bien, con la conquista de México por los castellanos se introduce la patología europea a toda Nueva España. Es bien sabido que los altísimos niveles de mortalidad registrados en esos siglos (1520-1833), obligaban a todas las instituciones $o$, mejor dicho, a toda la sociedad, a participar en los diversos rituales de la muerte, ya que ésta se convirtió en masiva, presente, constante y cotidiana (3). Así al revisar cualquiera de los periódicos y "diarios" novohispanos de los siglos XVII y XVIII, en los que solamente se consignan las muertes extraordinarias, es decir, aquellas que fueron dignas de ser noticia, resulta, que la muerte ocupó casi el sesenta por ciento de los sucesos referidos (4).

En estas condiciones los católicos debían de estar preparados para enfrentar a la muerte súbita, todos los días sin excepción.

Pero ¿qué pasaba con las ofrendas funerarias?, ¿se hacían?, ¿en dónde?, ¿cuándo?, ¿en qué consistían?, ¿eran realmente católicas o estaban integradas a las culturas nativas?, ¿quiénes hacían las ofrendas? y por último ¿a quién se le hacían?

\section{FUENTES}

Para contestar estas preguntas me he basado por un lado, en materiales documentales y por el otro, en las evidencias que han

(2) Manuel Toussalnt, Arte colonial en México. México UNAM. 1948; Juan de la ENCINA, "Del barroco europeo al barroco mexicano" en 40 siglos de arte mexicano. México, tomo 3, págs. 127-129; Victor L. TAPIE, Le baroque, Paris, Que sais-je?, 1974.

(3) Elsa Malvido, "Arca de Noé o Caja de Pandora" Suma y recopilación de pandemias, epidemias y endemias en Nueva España 1519-1810. Mexico, IMSS. México, 1992.

(4) Gregorio M. DE Guwo, Diario 1648-1664, México, Porrúa, Colección Escritores Mexicanos, 1953; José Gómez Moreno, Diario curioso y cuadernos de las cosas memorables. México, UNAM. 1986; Diario curioso del Capellán del Hospital de Jesús Nazareno, Edit. Luis Vargas Rea, México 1953; Juan Antonio Rivera, Diario curioso y exacto. Edit. Luis Vargas Rea, México 1955 y Antonio de Robles, Diario de sucesos notables (1665-1703). México 1703. 
encontrado los investigadores del Departamento de Antropología Física del Instituto Nacional de Antropología e Historia, durante los trabajos de rescate realizados en cuatro cementerios coloniales: Huxotla, Estado de México, San Jerónimo y Capilla del Convento del Carmen, Ciudad de México y Convento de Tlayacapan, en Morelos (5).

\section{FORMAS Y ELEMENTOS DE LA OFRENDA CRISTIANA}

\section{Formas}

Según las Siete Partidas de Alfonso X El Sabio, en la Partida IV la ley 6 describe y cuantifica las ofrendas que hacen los cristianos a Dios, en tres maneras:

La primera es cuando alguno da a Dios, o a la iglesia alguna cosa en su vida, quiere que sea mueble, o raiz.

La segunda, es cuando la hacen donación a otros a su finamiento, por aniversario, o por misas cantar.

La tercera, es aquella que hacen cada día al altar o al clérigo, besándole la mano. Y estas ofrendas son tenidos los hombres de dar a los clérigos de las iglesias parroquiales donde moran y reciben los sacramentos, pero bien pueden ofrecer a otras... si quieren.

Y como quiera que los clérigos son temidos de rogar a Dios por los hombres, que les perdone sus pecados, más lo deben hacer por las ofrendas que reciben de ellos (6).

\section{Elementos de la ofrenda}

Dos son los tipos de elementos que componían la ofrenda:

1. Objetos ideológicos o servicios ceremoniales religiosos, que incluían: toque de campana, visas, rosarios, sermones, confesión,

(5) Elsa Malvido, Josefina Mancilla, José Antonio Pompa, "Un cementerio indigena del siglo XVI, en Huexotla, Estado de México" Revista Trace. México, 1986, $\mathrm{n}^{2}$ 10, págs. 39-51; Roberto JiMÉNEZ DE OVANDO, La capilla mortuoria del Exconvento del Carmen, San Angel. D.F. México, SEP-INAH. 1980; Josefina MANCILLA, Carmen PuoAn, José Antonio Pompa y Guadalupe Villegas, "Estudios de stress en los entierros primarios del templo de San Jerónimo, Ciudad de México". Anuario de Antropologia Física, México, SEP-INAH. 1991; Arturo Oliveros, Las momias de Tlayacapan. México, SEP-INAH. 1990.

(6) Códigos españoles. Códigos de las Siete Partidas. Madrid. Imprenta de publicidad. Vol. I, pág. 280. 
extremaunción, olor del copal, fuego, viático, túmulos, procesión, entierro; con cruz alta o baja, capa, estola, hachas, pago de la ofrenda y del lugar del entierro, bendición y besamano del sacerdote, octavarios y novenarios.

2. Objetos materiales: cirios, vestido, caja o petate, túmulos, flores, rosarios, alas, clavos, cilicios, fuego, incienso, objetos asociados, objetos directos del ritual, medallas, coronas, vestidos y capas negras, comida, bebida, ayuno, obras pías, pinturas, herencias, casas, tierras, dinero, esclavos, etc. y el cuerpo mismo del muerto, en partes o en pedazos.

\section{Espacios y tiempos de la ofrenda}

Según los documentos hemos encontrado cinco espacios y nueve tiempos en los que se realizaba la ofrenda mortuoria durante el tiempo colonial. Los espacios eran:

1. La casa en donde habitualmente vivió y murió el individuo.

2. El espacio que hay entre la casa y la iglesia-cementerio.

3. El camposanto mismo.

4. La iglesia.

5. El pueblo.

Uno de los cambios sustanciales impuestos a todos los grupos nativos de Nueva España fue el enterramiento de sus muertos en un espacio santificado o camposanto integrado en la mayoría de los casos a la iglesia, convento, altar, o atrio, donde esperar la resurrección de los cuerpos. Resultaban así lugares centrales de las ofrendas funerarias por contener a los muertos de la comuni$\mathrm{dad}$, añadiéndose las sagradas reliquias que, generalmente existían en el altar, es decir parte de otros muertos. Por este carácter escatológico hubo etnias como los tobosos de Chihuahua, quienes se negaban a ir a las iglesias, pues decían que "esas eran las casas de los muertos a quienes ellos temían» (7).

(7) Carta Anua de 1597, en Documentos para la Historia de México. 4. ${ }^{\text {a }}$ serie, T. III. pág. 38. 


\section{CuAdro Ne 1}

TIEMPOS Y ESPACIOS PARA LA REALIZACIÓN DE LAS OFRENDAS

\begin{tabular}{|c|c|c|c|}
\hline $\begin{array}{l}\text { Tiempo de la } \\
\text { ofrenda }\end{array}$ & $\begin{array}{l}\text { Sujetos que } \\
\text { ofrendan }\end{array}$ & $\begin{array}{l}\text { Espacios de la } \\
\text { ofrenda }\end{array}$ & $\begin{array}{l}\text { Objetos de la } \\
\text { ofrenda }\end{array}$ \\
\hline 1. Antes de morir & $\begin{array}{l}\text { moribundo, } \\
\text { sacerdote, } \\
\text { cofradias, familia }\end{array}$ & iglesia-casa & $\begin{array}{l}\text { rezos, candelas, extre- } \\
\text { maunción, óleos, } \\
\text { agua, bebida, viáticos. }\end{array}$ \\
\hline 2. momento de morir & $\begin{array}{l}\text { muerto, } \\
\text { sacerdote, } \\
\text { familia, cofradias. }\end{array}$ & iglesia-casa & $\begin{array}{l}\text { rezos, campanas, ves- } \\
\text { tido, objetos, rituales, } \\
\text { velas, oración fúne- } \\
\text { bre, flores. }\end{array}$ \\
\hline $\begin{array}{l}\text { 3. transporte al } \\
\text { cementerio }\end{array}$ & $\begin{array}{l}\text { muerto, sacerdote, } \\
\text { familia, cofradias. }\end{array}$ & calles & $\begin{array}{l}\text { campanas, velas carro } \\
\text { za, cruz alta o baja, } \\
\text { hachas, procesión, } \\
\text { capas o lobas, flores } \\
\text { túmulos, altar, rezos. }\end{array}$ \\
\hline 4. entierro & $\begin{array}{l}\text { muerto, familia, } \\
\text { cofradias, sacerdote. }\end{array}$ & iglesia, cementerio & $\begin{array}{l}\text { flores, velas, tumba, } \\
\text { monedas, piedras, } \\
\text { verbenas, ropa, comi- } \\
\text { da, leche bebidas. }\end{array}$ \\
\hline $\begin{array}{l}\text { 5. convite de } \\
\text { entierro }\end{array}$ & $\begin{array}{l}\text { familia, } \\
\text { cofradías }\end{array}$ & casa & $\begin{array}{l}\text { comida, bebidas, } \\
\text { rezos y juegos. }\end{array}$ \\
\hline $\begin{array}{l}\text { 6. octavario o } \\
\text { novenario }\end{array}$ & $\begin{array}{l}\text { muerto, familia, } \\
\text { cofradias, } \\
\text { sacerdote }\end{array}$ & iglesia-casa & $\begin{array}{l}\text { rezos, campanas, } \\
\text { velas, flores. }\end{array}$ \\
\hline 7. honras fúnebres & $\begin{array}{l}\text { muerto, familia, } \\
\text { cofradias }\end{array}$ & iglesia & $\begin{array}{l}\text { sermón fúnebre al in- } \\
\text { divuduo y/o a partes } \\
\text { de él. }\end{array}$ \\
\hline $\begin{array}{l}\text { 8. aniversario o } \\
\text { cabo de año }\end{array}$ & $\begin{array}{l}\text { muerto, familia } \\
\text { comunidad, } \\
\text { sacerdote }\end{array}$ & iglesia-casa & $\begin{array}{l}\text { comida, misa ofrenda } \\
\text { a la Orden Religiosa } \\
\text { o Parroquia, velas, } \\
\text { campanas, flores. }\end{array}$ \\
\hline 9. fieles difuntos & $\begin{array}{l}\text { comunidad, familia, } \\
\text { sacerdote }\end{array}$ & iglesia-casa, pueblo & $\begin{array}{l}\text { misa, campanas, ver- } \\
\text { bena, fuego, comida, } \\
\text { rezo, bebida, (pulque), } \\
\text { velas, vino, flores, } \\
\text { habas. }\end{array}$ \\
\hline
\end{tabular}

\section{La ofrenda en cuanto al sujeto}

La ofrenda en cuanto al sujeto se puede dividir en:

1. Ofrenda que otros hacen para el muerto.

2. Ofrenda que deja el muerto antes de morir para su propio beneficio, testamento con obligaciones religiosas. 
3. Ofrenda que hace la comunidad a sus muertos.

4. Ofrenda que hace la comunidad religiosa de un cuerpo muerto, a la comunidad de fieles.

5. Ofrenda que da el sujeto de partes de su cuerpo muerto, por testamento.

Nos concretamos por ahora a hablar de la cuarta y de la quinta forma de la ofrenda, para encontrar su cercanía barroca con las ofrendas funerarias nativas.

\section{CASOS DE OFRENDAS HUMANAS EN EL BARROCO MEXICANO}

La obsesión de encontrar santos o casi santos en una sociedad mística, fue clásico del inicio de la iglesia católica, pero recupera su importancia por varios motivos: uno de ellos fue después del Concilio de Trento, por la idea de consolidar una nueva iglesia; paralelamente en América por la necesidad de afirmar la identidad social y religiosa, sobre todo después de haber desaparecido las dos o tres primeras generaciones de conquistadores. Por lo cual Nueva España requería individuos que en medio del desorden colonial, por la falta evidente de gobierno, se mostraran dignos representantes de Dios en la tierra. Casi al igual que en la Edad Media, cuando las familias poderosas deseaban tener su propio santo, acá las órdenes religiosas, ávidas de reconocimiento, determinan a sus venerables y los lóan.

1. Ofrenda que hace la comunidad religiosa del cuerpo de un muerto "venerable»

Los casos que aquí se refieren son los de aquellos individuos que por su vida ejemplar, virtuosa y casta, imitando a Cristo, la iglesia o algunos de sus miembros decidieron "venerarlos" sin llegar necesariamente al proceso real, legal, de santificación o de beatificación (8). Era indispensable que el individuo objeto de tal devoción hubiese fallecido.

El cuerpo de casi todos estos individuos hombres y mujeres, «muertos, permanecían incorruptos en estado de gracia y desprendiendo olores perfumados por años", con "olor de santidad»,

(8) Silverio de Santa Teresa, Historia del Carmen descalzo en España, Portugal y América. "Los estudios en la Reforma. Vidas de venerables..." Burgos 1940, T. IX. Tipografía del Monte Carmelo. 
y al ser sus carnes desenterradas se hallaron "tan hermosas y tiernas como un niño", "con expresiones sonrientes y plácidas»; decían de otros, que conservaban el calor por días y su "cuerpo era tratable como si tuviera vida" (9). Son muchos los ejemplos que se nos relatan en las historias de las diversas Órdenes Religiosas, pues esta conducta no era específica de un grupo o de un lugar. Citaré algunos de ellos que nos pueden servir de indicadores.

Fray Francisco Jiménez es un caso digno de ser destacado. Fray Jerónimo de Mendieta nos cuenta que estando este fraile gravemente enfermo en el convento de Tuxpa, Jalisco y siendo atendido por Fray Lúcas de Almodobar, enfermero, admirado éste último de la sencillez y bondad de Jiménez, "después de morir le cortó un dedo de la mano, que guardó durante más de un año entre su ropa. El dicho dedo, permaneció sin descomponerse, ni secarse, y daba tanta fragancia de olor que le confortaba, hasta que un día lo perdion (10).

Según el mismo Mendieta, otro fraile llamado Alonso de Escalona después de muerto, "quedó su cuerpo más hermoso que cuando era vivo. Los religiosos conociendo su santidad de vida... con mucha devoción le cortaron los cabellos de la corona y las uñas de los pies y cada uno de los frailes procuró alguna cosa del varón santo por pequeño que fuese o un pedacito de su hábito u otra cosa semejante" (11).

También citaremos a Fray Martín de Valencia, uno de los primeros doce franciscanos que llegaron a México, individuo virtuoso que después de haber sido enterrado en Tlalmanalco, Mendieta mismo estuvo para confirmar el hecho (mito) de la incorruptibilidad de su cuerpo, por más de treinta años y llevando a unos indios con barretas y palas para levantar la lápida y escarbar, encontraron solamente tierra, una tumba vacía. Después de esto, se dijo que el cuerpo había estado perdido durante otros treinta años. Los indios de Amecameca confesaron tener su ropa guardada como reliquia: "un cilicio de cerdas, una túnica muy áspera, dos casullas pobres de lienzo de la tierra y con mucho cuidado guardaron aquellas prendas que les harían mercedes y les protegerían". Ya recuperadas, las pusieron en la cueva de

(9) Fray Jerónimo de MENDIETA, Historia Eclesiástica Indiana. Estudio preliminar y edición de Francisco de Solano, Biblioteca de Autores Españoles, vol. 162, págs. 165, 178, 192, 194, 222 por citar algunos ejemplos. T. II, Madrid 1973, y SANTA TERESA [8], págs. 259, 291 y 535.

(10) Mendieta [10], pág. 192.

(11) Ídem, pág. 194. 
Amecameca en donde se encuentran hasta hoy. Del cuerpo no se vuelve a decir nada (12).

De la madre Isabel de la Encarnación, de la Orden de las Carmelitas Descalzas en Puebla de los Angeles, en el siglo XVIII, nos relatan que: «en hombros de sacerdotes la llevaron al sepulcro, cortándole los hábitos, el velo y parte de las manos para tener las reliquias de la santa y venerable virgen..., de la tarima en que dormía se hicieron cruces pequeñas y se ven y hacen mil milagros con estos despojos" (13).

Hay otro grupo de ofrendas de cuerpos que fueron exhumados esperando que se les encontrara casi santos, como sucede con Fray García de Salvatierra, al que desenterraron diez meses después de muerto, y encontrándolo intacto le arrancaron el pelo, la barba y le jalaron las orejas (14).

De los carmelitas descalzos, agustinos y franciscanos etc., en España, tenemos ejemplos similares de desenterrados y expuestos en estado de gracia, lo que nos lleva a suponer que había un «hambre» de reliquias, que todos, o casi todos, los sepulcros de las órdenes fueron violados por la propia Iglesia a pesar de la prohibición clara de Alfonso X. Los cuerpos se exhumaban, pero es obvio que se preparaban por médicos especializados, que posiblemente utilizaban yerbas aromáticas para ese fin, logrando el deseado olor de santidad y demorando el proceso de descomposición (15).

Para terminar con este punto, comentaré sobre el caso más extremo de la ofrenda de un cuerpo muerto relatado en Nueva España: se trata de las exequias de Fray Jordán de Santa Catarina, dominico, celebradas en Oaxaca en 1592.

Acabada (la misa) se trató de llevarle a la sepultura, aquí se desenfrenó la devoción, desbocado el afecto común, ninguno por grande o magistrado que fuese se negó ambicioso de las

(12) Mendieta, [10], pág; 148. "De cómo se perdió el cuerpo del varón de Dios Fr. Martín de Valencia"... pág. 152. "Cuando este bien aventurado falleció, pusieron a recado y guardaron con mucho cuidado las ropillas..."

(13) Ricardo MARTín, El gran arte de la pintura El barroco. México 1986, vol. XII, Salvat. S. A.

(14) Mendieta, [10] pág. 222 "estaba sin corrupción alguna, los ojos enteros, los cabellos y la barba como cuando murió, tan pegados, que con mucha dificultad le pudieron arrancar algunos. La ternilla de la nariz y las orejas sanas y buenas que tirando de ellas no había manera de dar de sí..., ni en la sepultura habia algún género de mal olor".

(15) Fray Agustín de la MADRE DE Dios Tesoro escondido en el monte Carmelo mexicano. México 1986, unam. pág. 363. Mendieta [10], Tomo II, págs. 165, 178, 192, 194. 
reliquias de aquel cuerpo; cuales embestían al cabello y temerariamente devotas le arrancaron a mechones el cerquillo, cual hacía precia de los hábitos y a desgarros procuraba despedazarlo, cual se apoderaba de los zapatos, desnudándole aquellos pies de siervo fiel que trepó tantos montes; para servirle a su Magestad pasaba ya a indecente fervor aquel tropel de tan confuso discurso, no bastaban para detenerles los ruegos lastimeros de los religiosos hasta que el Alcalde Mayor y ordinarios interpusieron con rigor su autoridad para que con sus ministros apartaran el gentío que tenía ya despegado y en paños menores el cuerpo, y menos el dedo de un pie del que corría sangre como el ojo de una fuente (16).

Esta tradición insisto, era muy antigua en Europa. Así sabemos que en 1500, en un pueblo de la Umbría italiana quisieron matar a un ermitaño (San Romualdo) para quedarse con sus huesos. La urgencia local de tener a su propio santo llevó a los católicos a graves necedades, como podemos constatar aquí y allá. El desmembramiento de los santos después de muertos, era un proceso lógico: así las manos de Santa Catalina de Siena están en Venecia disecadas, mientras los restos de todos los santos están diseminados por los santuarios del mundo cristiano.

\section{Ofrendas humanas indigenas}

Por su parte los indios, aunque con otros fines, no perdían ésta búsqueda mágica de la protección del muerto y en el barroco colonial hacían cosas similares a los castellanos, pero que por estar fuera del órden establecido se consideraban memoria de sus religiones paganas demostrando, a decir de la iglesia católica, su falta de razón y su primitivismo salvaje, por lo cual fueron perseguidos y enjuiciados, como veremos en los siguientes documentos.

(16) Francisco BurgoA, Geográfica descripción de la parte Septtentrional.. México 1934, Tomo I, pág. 143. En Valladolid, España sucedía lo mismo: Alberto María CARREÑo, en Fray Domingo de Betanzos fundador en la Nueva España de la venerable Orden Domínicana. México 1980, Enciclop. del Estado de Mexico págs. 221, 222. "Llegabánse a ver su rostro de ángel, que aunque con las muchas penitencias parecía en vida menos hermosa, cuando ya Dios le habían enjugado las lágrimas muy apacible y bien compuesta. Llegaban a porfía a besarle las manos y los pies, a quitarle la ropa por reliquias, cortando y rasgándoles mucha parte de ella; y si los frailes no le defendieran, le dejaron del todo desnudo. Era tanto el consurso de la gente y tanta la devoción que mostraban al santo, que aún el mismo cuerpo corría riesgo que lo desmembrasen, por enriquecer con las reliquias del Bienaventurado". 
El primero de ellos del siglo XVI, se localiza en un proceso del Ramo de Inquisición y se refiere a Chiapa de los Indios (Chiapas) al sur de Nueva España; en el se cucnta que unos indios iban a celebrar a una cueva, cada año, una fiesta a una calavera, a la que hacian ofrenda de sacrificio de gallinas y comida, después se bañaban y se emborrachaban, según declararon todos (17).

Mientras que otro documento que nos habla de uno de los grupos nativos del Norte, los Sinaloas, los cuales al estar librando una batalla contra la expedición española de conquista en su territorio nos dice, que habiendo matado a todos «el postrer fue el capitán Gonzálo Gutiérrez, que según después dijeron; se defendió grande rato con el machete de estos que llaman frejeral y con él derribó brazos y abrió cabezas... hasta que cansado cayó al suelo y de esta manera lo mataron. Y por haberle los enemigos hallado tan valiente, le descarnaron todo el cuerpo sin dejarle más que solamente los huesos asidos a las cuerdas y nervios y así lo colgaron de un árbol a la entrada del monte... Y así lo encontraron al otro día, el gobernador (quien dijo que)... había un indio muy emplumado y embijado arrimado a la osamenta... cantando a grandes voces y con una cañuela de carrizo (tocaba) en los huesos haciendo un son y bailaba muy a su guston (18).

Por último, tenemos en el pueblo de Tuxtla, otra vez al sur, (Chiapas) «los indios adoraban como Dios a un esqueleto, cuyos huesos lavados adoraban y pintaban, al cual elevan cánticos... se dijo que esos huesos son veneración de muchos naturales, donde le ponen fuego, olor y que circulan por diversos lugares y pueblos, en cuevas, hacen hartazgos, visten con máscaras y ropa de animales que hacen frente a la iglesia de la Santa Fé; los huesos dicen, son de un indio anciano principal de su gentilidad» (19).

\section{Ofrendas de cráneos}

Otra parte del cuerpo que tuvo un significado especial entre los diversos grupos nativos y cristianos fue el cráneo. El tzompantli (altar de cráneos) de los Mexica causó gran horror y repudio entre los castellanos, quienes los acusaron de salvajes y sangrientos. Pero casi un siglo después de la conquista, en 1612,

(17) Carlos Navarrete San Pascualito Rey y el culto a la muerte en Chiapas. Méxice 1982 UNAM. pág. 15.

(18) Antonio Nakayama (recop.), Relación de Antonio Ruiz (La conquista en el Noroeste), México 1974, INAH. Colec. Científica, $\mathrm{n}^{\circ} 18$ págs. 64-65.

(19) Navarrete, [17], pág. 18. 
las autoridades virreinales temiendo un levantamiento de negros, decidieron hacer justicia y poner ejemplo público, sentenciando a treinta y tres negros hombres y mujeres. A una cuadra de donde estuvo en Tenochtitlan el tzompantli mexica, levantaron treinta y tres horcas en donde ejecutaron a todos aquellos, después fueron decapitados por los verdugos y sus cabezas exhibidas en escarpias alrededor de la Plaza Mayor durante varios meses, hasta que la fetidez los obligó a quitarlas. Por la pestilencia que despedían al paso de los días se pidió al virrey diere orden que las bajasen y enterrasen. Las cabezas tuvieron un doble simbolismo para la Iglesia, por un lado era el escarnio mayor del enemigo por medio de la decapitación considerada como un segundo sacrificio después de la muerte. Los ejemplos de exhibición de cabezas de enemigos en Nueva España, fueron considerados para la Iglesia barroca y el gobierno virreinal «como trofeos de la civilización» (20).

La diferencia cultural era fundamental, consistía en que los nativos descarnaban las cabezas que posiblemente comían en forma ritual, evitando la descomposición de la carne, que al parecer para la cultura cristiana era clave, pues en contra del "olor de santidad" estaba el de la "hediondez de la carne» de los pecadores y peor si eran malos aprobados.

Por otro lado los jesuitas y franciscanos, en la zona norte de Nueva España, cuando fueron victimados por los nativos y sus cuerpos más tarde recuperados, sufrieron también el sacrificio de la decapitación, pues sus hermanos llevaron las cabezas a sus conventos y colegios para recibir la merecida veneración, en pago de su muerte sacrificada por Dios (21).

Otro suceso conocido por nosotros, es el robo del cráneo del beato franciscano Sebastián de Aparicio, el cual nunca se encontró. Su cuerpo momificado, que no incorrupto, se halla hoy expuesto en el convento de San Francisco en Puebla; tiene la cabeza restaurada en cera.

En Italia, la cabeza de Santa Catalina de Siena, fue objeto de veneración y poseerla dio lugar a graves pleitos entre los católicos italianos. Según sabemos, la cabeza de la santa rodó prácticamente por toda Italia.

Como conclusión de esta parte podemos decir claramente

(20) Vicente Riva Palacio, y Manuel Payno, El libro Rojo. México 1989. CONACULTA págs. 228-238 y NAVARRETE [17], pág. 20.

(21) José Neumann, Crónicas de la Sierra Tarahumara, Chihuahua, Col. Centenario Edit., Camino 1992. 
que no había mucha diferencia entre lo que hacían unos y otros, y que más bien la diferencia residía no en lo que se hacía, o como dijo el padre Burgoa a fines del siglo XVI, los indios de Oaxaca se sorprendieron porque los españoles ofrendaban alimentos en las tumbas de sus muertos mientras que a ellos se les prohibían estrictamente tales prácticas (22).

\section{Ofrendas de partes de un cuerpo muerto hechas por testamento}

Nos referimos aquí a aquellos personajes que por donación, patronato o conducta promotora de la religión, se sentían capaces de autoofrendar algunas partes de su cuerpo, para que permanecieran en diversas iglesias y conventos como reliquias protectoras.

Según los estudiosos de la muerte cristiana europea, esta era una tradición medieval y nos consigna diversos tipos de ofrendas (23). En Nueva España, el obispo Núñez de Haro y Peralta quien autoofrendó sus órganos, destinando: usu corazón y parte de sus entrecijos al coro de Santa Teresa; sus ojos, al coro de las capuchinas de Guadalupe; su hígado al colegio de Belém y su cuerpo en el presbiterio de la Catedral" (24). Como vemos la ofrenda de los órganos tiene una correspondencia con los símbolos religiosos a quienes se ofrendaban. Si su esqueleto lo encuentran hoy los antropólogos físicos, podrían decir que este cuerpo sufrió desmembramiento múltiple y sería difícil explicarlo en el contexto cristiano, aunque no barroco.

Por los rescates efectuados en el convento de San Jerónimo de Ciudad de México se pudo confirmar también el hecho de que este tipo de ofrendas en México, al igual que en Europa no eran míticas, sino reales; una víscera al parecer corazón o hígado, contenido dentro de un vitrolero con líquido, en una especie de

(22) BURGOA, [16]. Tomo I, pág. 143.

(23) Philipe ARIES, L'Home devant la mort. Paris Seuil 1977. págs. 204, 207, 256, 257, 380, 381. "Les entrailles de Guillaume le conquerant etaient a Chalus, son corps a, labbaye aux Dames de Caén, son coeur a la cathedrale de Rouen, Veaucoup plus tard. Le roi Charles V eut trois lombeaux, un de Coeur, un D’Entrailles, un de corps..." pág. 257, y Images de l'Home devant la mort. Paris 1983, Seuil. págs. 136-137. "Plaque rulumaire du coeur D'enguerrand VII, Seigneur de Coucy (XIV Siècle), Musé municipale, Soissons".

(24) Fernando Benitez, Historia de la ciudad de México. México Salvat 1984, T. IV, pág. 93. N. BoyadJian, El corazón, historia, simbolismo, iconografía. México 1980. 
relicario, protegido por cuatro pequeñas gárgolas, fue localizado debajo del altar central (25).

En la ciudad de Puebla, el convento de Santa Mónica también posee una de ellas, aunque no sabemos su paradero; se trata de un corazón, ofrendado por el obispo Manuel Hernández de Santa Cruz. En los documentos sobre su panegírico se notifica "Todos pensaban que en su testamento pidiese que su cuerpo fuera sepultado en el convento... del que era fundador, pero pide ser sepultado en Catedral, pero en donación... da su corazón,.... Posteriormente a las exequias normales a un hombre de tal jerarquía se le hizo un panegírico al corazón mismo. Los especialistas en testamentos me informaron que existen varios documentos de laicos con estas pretensiones (26).

Aún en 1832 en el México Independiente se continuaba esta costumbre pues en la localidad de Pinos, Zacatecas, el corazón de un obispo nacido allí, se depositó en la iglesia en una urna de metal, la cual se abrió recientemente para verificar su contenido, explicitado en una leyenda (27).

Podemos decir que el corazón ha sido una parte del cuerpo que casi universalmente ha tenido un significado especial. Para los cristianos, el corazón de Jesús traspasado por la lanza, derramó la última gota de sangre por la salvación de los pecadores, y en el barroco mexicano, su veneración creció por medio de la propagación de las imágenes de los sagrados corazones de Jesús y de María. La devoción extrema como hemos visto, corporizaba a la ofrenda.

Por otro lado carecemos de documentos coloniales que hablen de sacrificios de corazones entre los nativos, pero sabemos que por lo menos para los mexica y otros grupos mesoamericanos significaba casi lo mismo que para la Iglesia Católica: «era el centro vital y órgano de la conciencia" (28) de aquí que ya "cristianizados", el culto al Sagrado Corazón, mantenga hasta nuestros días, un culto muy especial en México.

(25) Mancilla y otros [5].

(26) José Gómez de la Barra, Panegírico funeral de la vida en la muerle de el Exmo. Doctor don Manuel Fernández de Santa Cruz, obispo de la Puebla de los Angeles en Nueva España. Puebla, Biblioteca Fr. BN. R. 1558 LAF y AGN. Ramo Vinculos, 175. El Marqués de Ovando dona su corazón al altar de la iglesia de Cáceres, España, pero muere en un viaje por mar y la esposa no encontrando a bordo ningún médico, decide echarlo al mar. (Información dada por Verónica Zárate).

(27) Información dada por la historiadora Alicia Bazarte, diciembre, 1993.

(28) Alfredo López Austin, Cuerpo humano é ideologia. México UNAM. T. VI. pág. $187,1989$. 
Por su parte el pueblo o vulgo imitando estas conductas ejemplares, sólo podía ofrendar a Dios o a los santos reproducciones de parte de sus cuerpos, los milagros o exvotos; eso sí, en México para que tuvieran valor, debían de ser de oro y plata, cuando en España y Portugal eran de cera blanca o de escayola. La primera ofrenda cristiana de este tipo en Nueva España, fue hecha por Hernán Cortes: un alacrán de oro, enviado a la Virgen de Guadalupe de España por haberle salvado del piquete de este insecto, al ser invocada su protección (29).

De esta manera cualquiera podía substituir su cuerpo vulgar con valor real. Brazos, piernas, cuerpos, niños, niñas, mujeres, hombres, corazones, animales, etc., aparecen of rendados en las iglesias para solicitar la curación, la salvación o la restitución, física o moral.

\section{La mortaja o el vestido de entierro}

Ahora pasaremos a analizar otro de los objetos de la ofrenda, que ligará durante el barroco nuevamente al mundo indígena, con el occidental, o mejor dicho, con el ritual universal. Dentro del uso cristiano volvemos a Las Siete Partidas. En ellas se habla de la prohibición que había de vestir elegantemente a los muertos o con alhajas.

Sino a personas ciertas, así como a Rey, o a Reyna o a alguno de sus hijos, o a otros hombres honrados, o a caballeros, a quien soterrasen según la costumbre de la tierra, o a obispo, o a clérigo, o a quien deben soterrar con las vestimentas que les pertenecen, según la orden que han... y dan tres razones: La primera porque no tiene pro a los muertos en este mundo, ni en el otro.

La segunda, porque tienen daño a los vivos, si las pierden metiéndolas en el lugar donde no las deben tomar.

La tercera, porque los hombres malos por codicia de tomar los ornamentos que les meten, quebrantan los viceles, y desostierran los muertos (30).

Podemos afirmar que es cierto que sólo los rices o pederosos eran quienes tenían un lugar especial dentro de la iglesia-

(29) Artemio de Valle Arizpe, "El exvoto" en Notas de Platería, México, 1941. págs. 103-109.

(30) Códigos Españoles. [6]. Tomo I, pág. 228. 
cementerio y que podrían asegurar que no fueran violados sus sepulcros o sus cuerpos. Sin embargo, con el paso del tiempo se han encontrado en Mexico saqueos precisamente en aquellos entierros que se suponían protegidos, en parte, porque los ladrones esperaban encontrar objetos de valor y en parte porque las Leyes de Reforma no impidieron que esto sucediera.

Tenemos los siguientes casos de sepulcros violados: Antes de que los antropólogos llegasen a restaurar el convento de San Jerónimo (Ciudad de Mexico) varios ataúdes habían sido removidos abiertos y tomados algunos de sus huesos. Lo mismo sucedió en la capilla Mortuoria del Exconvento del Carmen, en San Ángel (Mexico DF). Ambas violaciones no ha podido fecharse con exactitud pero, fueron realizadas en este siglo (31).

Otro modo de conocer el traje español se debe a vista de ojo, pues gracias a los efectos de momificación o esqueletización en los cuerpos mismos y a la costumbre barroca de pintar a los humanos muertos, podemos saber cual era la ropa de enterramiento, sobre todo, la usada por los religiosos y las clases altas. Numerosos monjes del Exconvento del Carmen, y de San Jerónimo así como otros cuerpos de civiles de clase alta sepultados en el convento de Tlayacapan (Morelia) se han rescatado en estado de momificación, sus ropas están muy bien conservadas y nos dejan ver las costumbres mortuorias in situ.

Las Órdenes religiosas se enterraban a sus difuntos con sus hábitos, cilicios, medallas y rosarios. Las madres superioras se diferenciaban de las comunes por su pectoral y otras con tocado de flores. Algunos individuos masculinos, civiles adultos, que pertenecieron a una cofradía nos muestran sus ropas de diario y sobre ellas el hábito de San Francisco, en Tlayacapan. Las mujeres adultas vestían más sencillo, tenían coronas de flores y las doncellas una palma tejida en las manos.

En cuanto a los niños, llamados por la iglesia «angelitos», se les vestía como tales, con alas de alambre cubiertas de tul, vestido de blanco o azul celeste, algunos tienen en una mano los símbolos de la pasión de Cristo, los tres clavos; y en la otra, la palma de la virtud, elementos destacados en el barroco. Los más ricos vestían de gala, con telas importadas de Asia y Europa, holandas, brocados, encajes y gasas, cintas doradas, perlas y piedras preciosas, tocados con coronas de flores y espinas.

Ya entrado el siglo XIX, la marquesa Calderón de la Barca, consigna un caso sucedido en la Ciudad de México donde fue

(31) Mancill.a, [5] y JimÉnez de Ovando, [5]. 
vendido un vestido de novia, costosísimo, con el que había sido enterrada una prominente condesa. El sacristán que guardaba la llave de la cripta quitó el vestido de la novia muerta y lo vendió a una bailarina francesa de «infima calidad», y está fue identificada con él. Posteriormente el sacristán que lo vendió paró en la cárcel (32).

A pesar de la prohibición y recomendación de las Siete Partidas de no vestir a los muertos, en la barroca Nueva España el lujo se llevó hasta la tumba, manteniendo en el mundo subterráneo las grandes diferencias sociales.

\section{El vestido indigena}

En el otro mundo, el fraile Jacinto de la Serna nos dice haber visto cómo a los indígenas cuando morían se les ponía ropa limpia y nueva (33). Sin embargo, este hecho no se ha corroborado debido a que el único cementerio indígena colonial que conocemos (Huexotla) no nos ofreció ningún dato sobre la vestimenta, ya que los indios se enterraban en forma directa y con el paso del tiempo lo único que nos ha permitido recuperar es un pedazo de petate, que también era usado para envolver al muerto desde la época prehispánica. Práctica que puede verse en los bultos funerarios dibujados en los códices y hasta hoy día, como supervivencia, en los dulces de azúcar coloniales que representan a los "muertos pobres" como empetatados; de donde proviene el dicho de fulanita ya "se petateo", como sinónimo de "se murió".

No obstante la pobreza indígena postconquista en casi todos los entierros indígenas cristianos, se han encontrado objetos asociados en parte al ritual cristiano y en parte al indígena: un collar de cuentas de madera torneada, monedas de plata de la primera acuñación novohispana, medallas cristianas, cuentas de rosarios, cuentas de vidrio verde y otros objetos de plata pequeños no identificados (34). Sobre el ritual indígena ya sincrético, en el siglo XIX el padre Pérez, vio que echaban dinero a la boca de un difunto. De donde suponemos que todos estos objetos

(32) Marquesa de Calderón de la Barca, la vida en México. México, Porrúa 1948, pág. 65.

(33) Jacinto de la SERNA, Tratado de idolatrias supersticiones, Dioses, ritos, hechicerias y otras costumbres gentilicias de las razas aborigenes de México. Edit. Fuente Cultural. pág. 69, 111.

(34) José Antonio POMPA "La numismática, auxiliar en la investigación arqueológica". En Boletín del INAH. México, 1975 n 13, Epoca II. págs. 59-61. 
pueden haber sustituido al chalchihuite, o piedra verde, que servía para el pago al remero: el actual nos llevaría al inframundo de ahora, al cielo cristiano, y a éste sabemos pagarle con objetos de la cultura occidental.

\section{OBSERVACIONES FINALES}

Como hemos visto el hombre no ha dejado de tener temor ante la muerte, la desaparición real de la vida nos lleva a proteger al muerto por un lado y a protegernos de él también. Así al fiambre se le adora, baila, ora, santigua, contempla, mistifica o mítifica, pero además se le rescata. Se usa como protector, claro que lo que más resiste el paso del tiempo son los huesos por lo tanto, son los restos oseos en las diversas culturas las que tienen un lugar muy especial en el ritual luctuoso como memoria de la comunidad.

De este trabajo se puede concluir que el mundo de la muerte es amplísimo y muy complicado, sin importar la cultura que se estudie. Sin embargo, según Octavio Paz y otros políticos, poetas, literatos y pintores, que no historiadores, nos han hecho creer que a los mexicanos tenemos una fijación por la muerte y que sus raíces provienen de la época prehispánica. Esto se debe, entre otras cosas, a que el tema como dije al principio, no se ha investigado en profundidad para poder afirmar que nuestra idea de la muerte hoy se origina en el sincretismo ideológico de las múltiples culturas anteriores o de la conquista del mundo católico, que obviamente por las condiciones históricas, todas creaban mundos escatológicos. Para nosotros la muerte barroca colonial se parece mucho aún a la que vive el mexicano del campo (con sus grandes variantes locales), donde el subdesarrollo ha permitido que la muerte continúe siendo constante y presente, ensañándose principalmente con los niños, obligando a la población a mantener la creencia de que la muerte de un hijo es la muerte de un angelito, evitando así el entristecerse por la pérdida de lo más preciado (por lo menos para la madre) ya que él servirá de intermediario entre su familia y Jesucristo para conseguir bienaventuranzas a los vivos.

Es claro que en la época colonial las pandemias sobre todo la peste bubónica, arrancaba entre el $50 \%$ o el $90 \%$ de los habitantes cada vez que aparecían, siendo desconocida esta forma masiva de muerte hasta antes de la llegada de los castellanos. Lo que no 
quiere decir, que aquí se viviera en el edén o en el jardín de la juventud, pero sí podemos afirmar que las dimensiones y la velocidad de la muerte variaron sustancialmente con la imposición de la nueva patología. Sin embargo nos resulta curioso que los europeos laicos de hoy, hayan olvidado su brutal amor divinizado a la muerte, que durante siglos nos ofreció la Iglesia cristiana, e insistan en que nosotros "la jugamos", "nos burlamos", siendo sólo por medio de la lírica infantil castellana cuando esto sucedió: estaba la media muerte sentada en un muladar, comiendo tortilla dura pa ver si podia engordar.

Espero que ahora nos replanteemos el concepto de la muerte del mexicano y no olvidemos que tres siglos de cultura occidental, de intenso amor a la muerte, algo nos habrá dejado a los vivos de hoy. 